\title{
Investigating the mobility capabilities and functionings of children
}

A quantitative assessment of preschools and nurseries in São Paulo (Brazil).

\section{Abstract}

(200 words)

Despite being recognized as an appropriate tool to address different dimensions of transport-related social exclusion and inequalities, the Capability Approach still lacks application within the urban mobility domain. This study conceptualized the vectors of mobility capabilities and functionings of preschools and nurseries (children up to 6 years old) in São Paulo, Brazil. From the location of 203 schools (of which 109 are public), an indicator of mobility capabilities was estimated using georeferenced datasets relating to mobility, street network, road safety, and the built environment in the surroundings. The schools were analyzed according to their level of mobility capabilities and the corresponding capacity to promote pedestrian mobility, i.e., the agency of each school. Results pointed out that public schools present share of pedestrian trips two times higher and average walking time $30 \%$ higher than private schools. Schools with positive agency (mostly the public ones) seem to require the upgrading of existing pedestrian trips to school that are performed under inadequate conditions through investments in the built environment. On the other hand, schools with negative agency (mostly the private ones, generally located in places with less barriers to walk) might require educational programs for motivating higher levels of use of active modes.

\section{Keywords}

Urban mobility; children and youth; Latin America; right to the city. 


\section{Manuscript}

(7757 words, including references and table/figure captions)

\section{Introduction}

In the last decades, much has been written about the role of urban mobility to achieve social justice. However, changes in public policies towards territorial equity have found increased opposition not only in the public sector (from municipalities to the national government), but also in civil society (citizens, corporations and social movements), with important decision makers increasingly overlooking the impacts of transport on climate change, public health, and socio-spatial disaggregation, among others (Martens 2017; Richter, Friman, and Garling 2010). In this sense, public agencies and advocacy-led organizations have identified in schools a set of relevant factors to increase the right to the city through the promotion of permanent changes in transport practices. These refer mainly to the initiatives regarding the promotion of active mobility, which includes walking to relevant destinations, such as school.

One can identify several commonalities of the Capability Approach (CA) with topics on the generation and inducement of demand in transportation, such as the intersection of the basic claim of asking "what people are able to do and what lives they are able to lead" under the Capability Approach (Robeyns 2017) with the need for understanding the travellers' responses to transportation policies through a more behavioural-oriented approach (Van Acker, Van Wee, and Witlox 2010). Also, there is prevalent features between the CA's focus on the individual's capability that enable people to achieve relevant functionings from their own capability sets (Robeyns 2017) and the conceptual framework that seeks to understand latent travel demand (Clifton and Moura 2017). The emphasis on the active mobility set in this work is grounded on the relevance of walking, cycling, playing and other so-called active modes of transport to combine themes of equity and social exclusion, overlooked constantly in transportation studies (Martens 2012; Lucas, van Wee, and Maat 2016).

By focusing on walking and its intersection with the quality of the built environment, some works identified the significance of promoting walking in the open public space regarding i) the alleviation of childrens' and caregivers' accessibility shortages (Sirard and Slater 2008; Babb et al. 2016); ii) the change of transport habits towards territorial equity (Pereira, Schwanen, and Banister 2017); and iii) the development of core skills for children that are activated through walking and staying in the public space, such as the social and cognitive capacities (Waygood and Cervesato 2017; Shonkoff and Phillips 2000).

When developing empirical applications based on the capability approach, especially when one is combining specific features from education and transportation studies, the "selection of valuable functionings that fit the purpose of the theory or application" (Robeyns 2017) seems imperative. A significant contribution is brought by Biggeri and Libanora (2011), who operationalized the Capability Approach together with children (aged 11-17). They highlight the potential of the CA for understanding children's well-being and include core concepts of urban mobility in their list of capabilities, e.g. mobility and time-autonomy, which are considered important or very important by the majority of children (idib.). Especially as one regards the access to school by active modes, in which the children are exposed to the conditions of the public spaces, the capabilities that were most valued by children (education, participation and social relations, for example) acquire a central 
role to underlie the appraisal of the issue of walking to and from school (Ulset et al. 2017; Carver et al. 2005).

Despite being widely applied across disciplines, the CA lacks conceptualization within the domain of urban mobility and the collective setting of nurseries and preschools. In this sense, it is relevant to look for the correspondences of the CA with pertinent aspects concerning the daily mobility of children, especially the ones that regard the access to relevant destinations through walking. Nevertheless, contributions on the intersection of these topics are still scarce, in which little attention has been given to the potential of the CA for understanding children's well-being (Biggeri and Libanora 2011; Leßmann 2016).

In the search for the incorporation of the CA into the quantitative methods that are used in transport research, Eda Beyazit (2011) seeks an appropriate methodology for measuring distributional issues in transport, in which she proposes the conceptualization of capabilities and functionings within the transport domain. Following Beyazit's work and relying on widespread contributions about the CA (Kuklys 2005; Nussbaum 2007; Robeyns 2017), the concepts of agency and conversion factor can be outlined in the context of urban mobility and the access to schools, as follows. These are expected to guide the application of the Capability Approach in the quantitative assessment of the access to preschools and nurseries by children through walking, which is expected to inform public policies and guide empirical research.

Table 1: Proposal of CA concepts within the domain of active mobility and the access to preschools and nurseries by children. ${ }^{a}$ Based on Kuklys (2005), Nussbaum (2007), Ballet, Biggeri, and Comim (2011), and Beyazit (2011). ${ }^{b}$ Based on

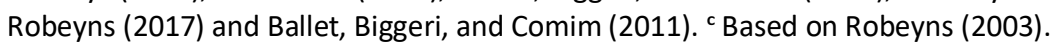

\begin{tabular}{|c|c|}
\hline CA concept & Description (domain of active mobility and the access to school by children) \\
\hline Capability & Ability to achieve valuable activities through movement or stay in the public space ${ }^{\text {a }}$ \\
\hline Functioning & $\begin{array}{l}\text { Actual degree to which valuable activities are successfully achieved through movement or stay in the } \\
\text { public space a }\end{array}$ \\
\hline Agency & $\begin{array}{l}\text { Capacity to convert abilities (latent qualities) to achieved functionings; Degree of achievement of } \\
\text { functionings from the given abilities/conditions }{ }^{\text {b }}\end{array}$ \\
\hline $\begin{array}{l}\text { Conversion } \\
\text { factor }\end{array}$ & $\begin{array}{l}\text { Personal, social and environmental characteristics that influence the relationship between the good and } \\
\text { the functionings to achieve certain beings and doings, such as gender, societal hierarchies, and } \\
\text { infrastructure }^{c}\end{array}$ \\
\hline
\end{tabular}

Within the transport literature, there is a well-established work concerning the issue of active commuting (pedestrian and cycling), school transportation, and social justice in transportation, which play a fundamental role for many of the aspects considered in this work (cf. Kerr et al. 2006; Schoeppe et al. 2013; Mitra 2013). Despite being predominantly applied in developed countries, the extensive number of empirical studies might greatly support the identification of variables that might encourage or hinder the access to schools by children through walking in this study. These are summarized in Table 2, as follows.

Table 2: Correlates of active commuting to school. Adapted from Sirard and Slater (2008). Fields with light shading indicate non-null values.

\begin{tabular}{llll}
\hline Variable & Direction of association (number of studies) \\
& Positive & Null & Negative \\
\hline
\end{tabular}




\begin{tabular}{llll}
\hline Street network densely connected & 1 & 3 & 0 \\
Existence of direct route to school & 0 & 1 & 1 \\
Quality/existence of sidewalks & 2 & 1 & 0 \\
Population density (higher) & 1 & 0 & 0 \\
Insertion into urban area & 1 & 0 & 0 \\
\hline
\end{tabular}

To further assist the development of the framework for assessing schools through a quantitative approach, a tool developed by the World Health Organization for measuring health and disability is considered here. As presented by Trani, Bakhshi, and Biggeri (2011) on the consideration of children's disabilities through the CA, the ICF (International Classification of Functioning, Disability and Health) provides a 36-item survey covering six domains of functionings, including mobility, life activities, cognition, participation, interaction with people, and self-care (WHO 2013). To score the ICF items, one of the five following values are assigned to responses: No difficulty; Mild difficulty; Moderate difficulty; Severe difficulty; Extreme difficulty or Cannot do. Besides identifying mobility in the framework of CA domains, it is possible to highlight a reduced set of capabilities that are highly interconnected with the subject of children walking to school, such as getting out of your home (item D2.4); walking a long distance such as a kilometre [or equivalent] (D2.5); learning a new task, for example, learning how to get to a new place (D1.4); and dealing with people you do not know (D4.1). A shorter 12 -item version of the ICF survey, which explains $81 \%$ of the variance of the 36 -item version, contains all items previously cited but D2.4 (ibid.). In this sense, it seems appropriate to consider the issue of children accessing schools through walking in the public space.

The study here presented seeks to examine and conceptualize the vectors of capabilities, functionings, and agencies of preschools and nurseries in the city of São Paulo (Brazil). These relate mostly to the issues of access of children (aged 0-6) and their caregivers to the city when walking in the public space to and from schools, in which the CA is expected to support planning concepts and applications in the context of Latin American cities.

\section{Data}

This study is based on the open-access dataset containing preschools and nurseries in the municipality of São Paulo ( $N=4570$ ), which provides information about their school type (public/private) and location. The dataset underlay the generation of circular buffers (Euclidean distance) and service areas (along the street network) around schools with radiuses of $500 \mathrm{~m}$, $1,000 \mathrm{~m}$ and $2,000 \mathrm{~m}$. From the location of schools, information from other georeferenced datasets was incorporated relating to the mobility functionings, the street network, the road safety, and the quality of the built environment of the surroundings of schools at different levels of analysis, i.e., circular buffers of $500 \mathrm{~m}, 1,000 \mathrm{~m}$ and $2,000 \mathrm{~m}$ and service areas of $500 \mathrm{~m}, 1,000 \mathrm{~m}$ and $2,000 \mathrm{~m}$.

The data on mobility derived from the 2007 disaggregated dataset of the decennial Metropolitan OD survey performed by METRO-SP ( $N=196,698$ trips). To filter out the trips to preschools and nurseries performed by children, only the trips made by children aged up to 6 , enrolled in a preschool or nursery in the municipality of São Paulo, and whose purpose either in origin or destination is education were selected. That yielded a reduced sample of 3,740 trips, for which expansion factors ( $m=207.9 \pm 58.1 \mathrm{Cl}$ (95\%) were associated. For each trip, coordinates of the schools were provided, which enabled the association with the open-access dataset obtained. For 
that, a limit of $1,000 \mathrm{~m}$ of linear distance was considered between the location of the school from the base dataset (assumed as correct) and the school locations estimated from the plotted coordinates. These procedures were performed for public and private schools separately. From a set of 1,517 unique values of school coordinates provided, 970 were assigned to 509 different schools. Finally, only the schools that presented more than 100 trips were considered valid for further analyses, which yielded the definitive sample of 203 schools, of which 109 are public.

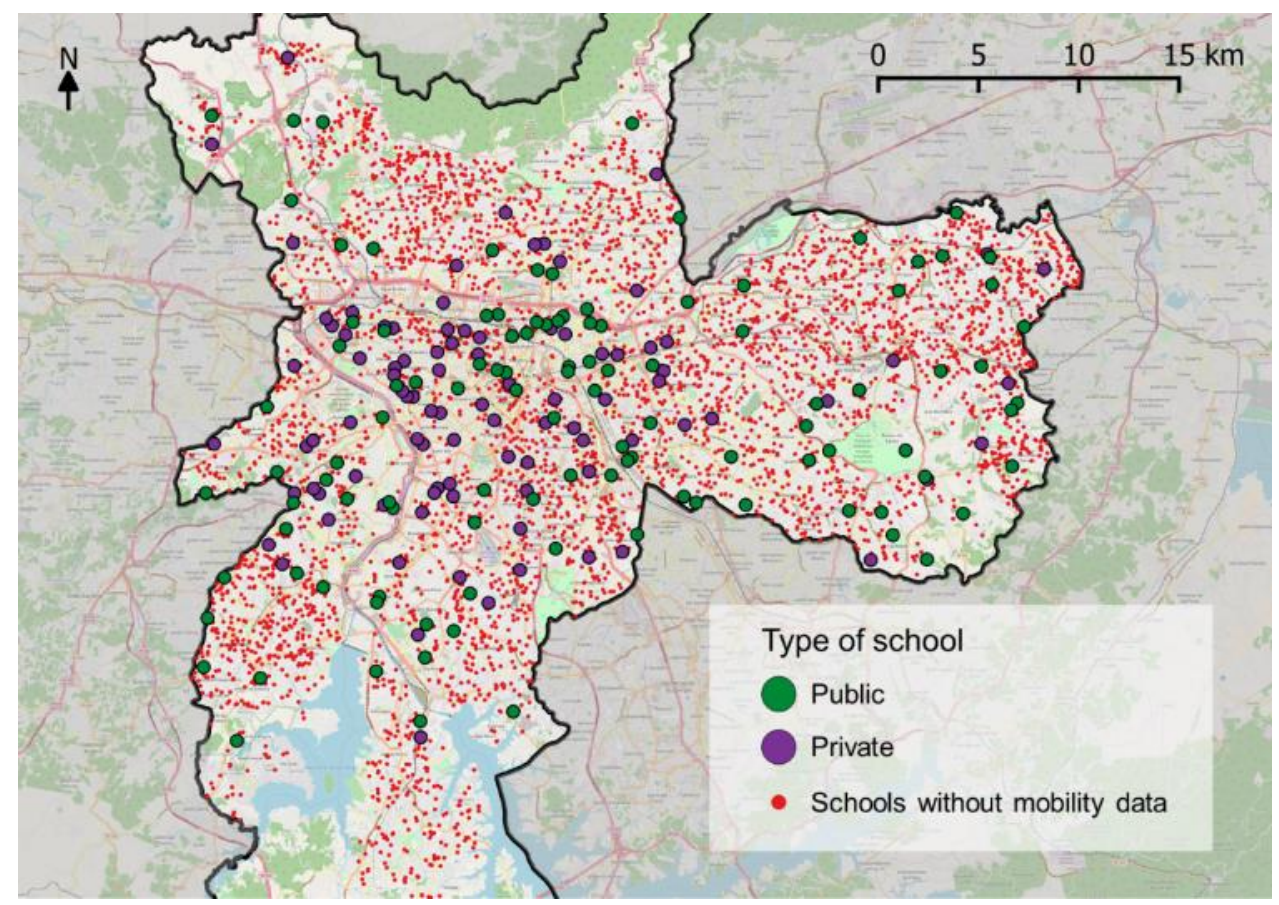

Figure 1: Spread of preschools and nurseries containing data on mobility $(\mathrm{N}=203)$ according to type of school (public/private)

The information on the street network derived from the OSMnx open-source Python package developed by Geoff Boeing (2017), in which a set of network measures are automatically calculated for the set of circular buffers and service areas around schools, whose description is provided as follows.

Table 3: List of measures on street network and respective description collected from OSMNx Python package for generated circular buffers and service areas around schools. Adapted from Boeing (2017).

\begin{tabular}{ll}
\hline Measure & Description \\
\hline Intersection density & $\begin{array}{l}\text { Number of intersections in the network divided by area (of circular buffer/service area) in square } \\
\text { kilometers. }\end{array}$
\end{tabular}

Density of street Number of edges in the undirected representation of network divided by area segments

Street density Total street length divided by area

Average circuity Total edge length divided by the sum of great circle distances between the nodes incident to each edge. It indicates the lack of straightforwardness in the available routes to school 


\begin{tabular}{ll}
\hline Measure & Description \\
\hline $\begin{array}{l}\text { Average closeness } \\
\text { centrality }\end{array}$ & $\begin{array}{l}\text { Average of the distance from the nodes to all other nodes in the buffer/service area, weighted by } \\
\text { length. It indicates the direct connections of the school to the other nodes within the urban street } \\
\text { network of the school surroundings. } \\
\text { Average betweenness } \\
\text { Average value of the fraction of all shortest paths that pass through the nodes of the buffer/service } \\
\text { area, indicating the number of times a node lies on the shortest path between other nodes. It } \\
\text { represents the influence of the school on the flow of the school surroundings. }\end{array}$ \\
\hline
\end{tabular}

The data on road safety for the surroundings of schools stemmed from the inventory of road crashes collected by the Municipality of São Paulo from 2009 to 2017 ( $N=187,451$ ). To identify the ones that are relevant to indicate the degrees of road safety around preschools in nurseries, only the pedestrian-car crashes during school drop-off and pick-up (weekdays at either 6:45-7:15am, 4:45$5: 15 \mathrm{pm}$ or $6: 45-7: 15 \mathrm{pm}$ ) were filtered out, resulting in 12,885 cases. These were then intersected with the school surroundings (circular buffers and service areas $500 \mathrm{~m}-2,000 \mathrm{~m}$ ).

The conditions of the built environment around preschools and nurseries were collected primarily from the decennial national census promoted by the Brazilian Institute of Geography and Statistics (IBGE), whose latest dataset (2010) was processed to collect a set of variables regarding the surroundings of schools. The levels of social vulnerability calculated by the SEADE Foundation (SEADE 2012) were also incorporated into the obtained circular buffers and service areas, as follows.

Table 4: List of measures on the built environment and respective description collected for generated circular buffers and service areas around schools $(500 \mathrm{~m}, 1000 \mathrm{~m}$ and $2000 \mathrm{~m})$. Adapted from IBGE (2011) and SEADE (2012).

\begin{tabular}{|c|c|}
\hline Measure & Description \\
\hline Population density & Resident population in the school surroundings \\
\hline $\begin{array}{l}\text { Percentage of population by skin } \\
\text { color/ethnicity }\end{array}$ & Percentage of white/black population in the school surroundings \\
\hline Percentage of population aged 0 to 6 & Percentage of population aged 0 to 6 years old in the school surroundings \\
\hline $\begin{array}{l}\text { Percentage of population with high social } \\
\text { vulnerability }\end{array}$ & $\begin{array}{l}\text { Percentage of the resident population in census tracts presenting high or } \\
\text { very high levels of social vulnerability in the school surroundings }\end{array}$ \\
\hline $\begin{array}{l}\text { Percentage of areas with high social } \\
\text { vulnerability }\end{array}$ & $\begin{array}{l}\text { Percentage of area of census tracts presenting high or very high levels of } \\
\text { social vulnerability in the school surroundings }\end{array}$ \\
\hline Percentage of urban area & Percentage of urban area in the school surroundings \\
\hline Per capita income & Average monthly income of resident population in the school surroundings \\
\hline Coverage of street lighting & $\begin{array}{l}\text { Percentage of households with the presence of street lighting in the school } \\
\text { surroundings }\end{array}$ \\
\hline Coverage of paved streets & $\begin{array}{l}\text { Percentage of households with the presence of paved streets in the school } \\
\text { surroundings }\end{array}$ \\
\hline Coverage of sidewalks & Percentage of households with sidewalks in the school surroundings \\
\hline Coverage of vegetation & Percentage of households with vegetation in the school surroundings \\
\hline Presence of open sewage & Incidence (\%) of open sewage near households in the school surroundings \\
\hline Presence of litter & Incidence (\%) of litter near households in the school surroundings \\
\hline
\end{tabular}

To incorporate the data from the census tracts to the limits of the school surroundings (circular buffers and service areas), the open-access QGIS intersection tool was used to identify which census tracts intersect with the limits of the surroundings, either partially or entirely. The absolute 
measures (e.g., population, number of households, urban area) were calculated proportionally to the areas of the intersected features. That enabled the computation of the relative measures, such as the population density (sum of the population of the intersected areas divided by the area of the circular buffer/service area) and the presence of litter (sum of the households with presence of litter in the intersected areas divided by the sum of all households in the intersected areas).

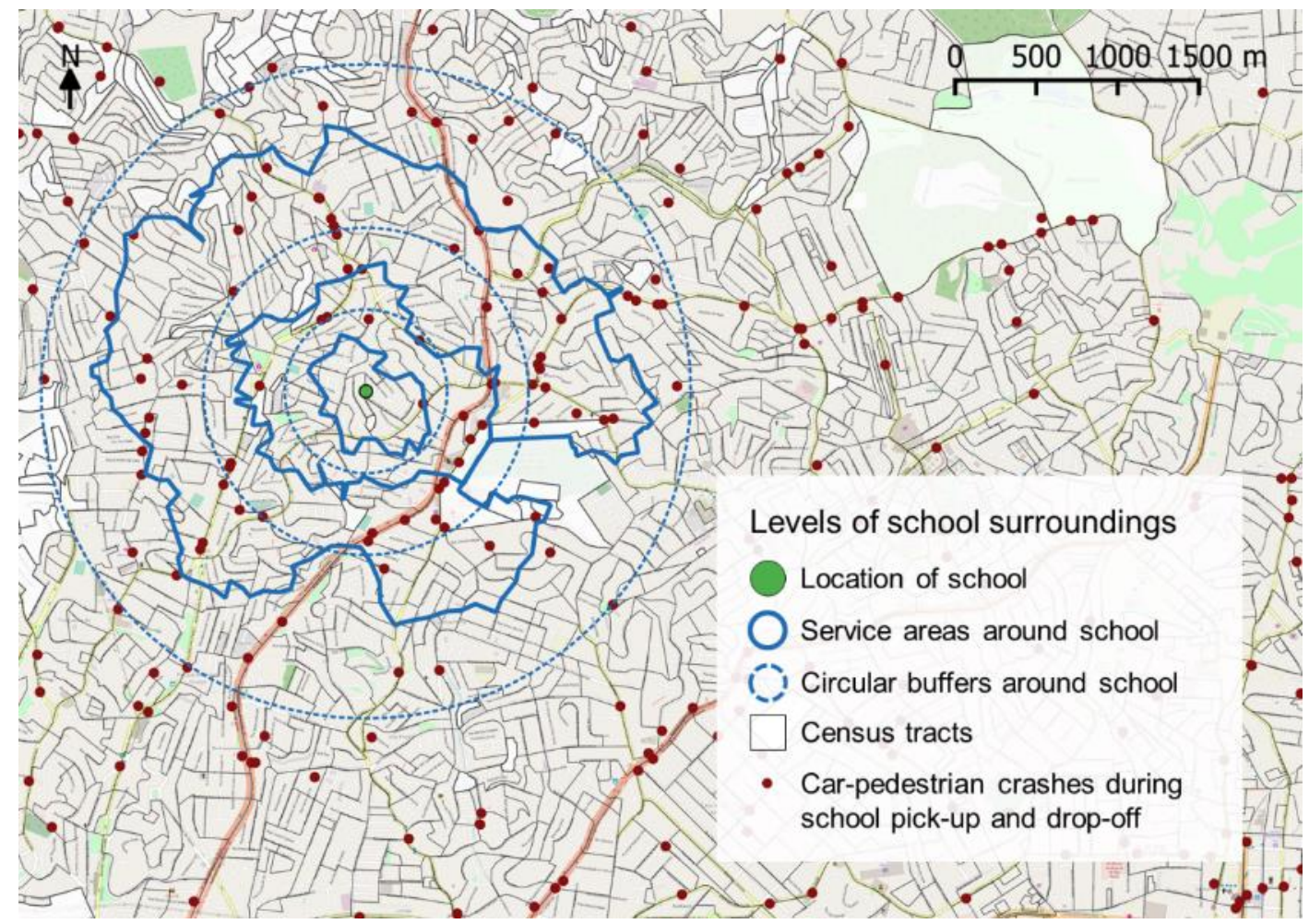

Figure 2: Circular buffers and service areas of selected schools: example of intersection of school surroundings with census tracts and road crashes.

\section{Methods}

To compose the indicator of mobility capabilities of nurseries and preschools, some procedures were implemented to reconcile urban mobility quantitative methods with the concepts from the Capability Approach. In addition, the adopted methods followed the perspective of emerging social movements and transport advocates in Latin America, which enact pedestrian mobility as the backbone of urban mobility towards the right to the city (Vasconcellos 2018; Harkot et al. 2017).

First, we classified the variables collected according to their potential to indicate greater conditions for walking to and from school, i.e., whether they could integrate a compounded indicator of mobility capabilities (capability metrics) or contribute to the identification of factors that may influence the proper achievement of active mobility (potential conversion factors).

After classifying the collected variables into capability metrics or conversion factors, the collected variables are categorized according to their buffer type (circular buffer or service area) and level of analysis (radius of $500 \mathrm{~m}, 1,000 \mathrm{~m}$ and 2,000m). For the ones classified as capability metrics, the sign of the contribution of the variable to the capability indicator is also defined, whether it is expected to influence positively or negatively the levels of mobility capabilities. For example, higher rates of road crashes might indicate lower levels of mobility capabilities (negative sign); greater intersection densities in the surroundings of schools might facilitate the promotion of walking to school (positive 
sign). The definition of these signs is based on the literature review, on participatory surveys and the informed awareness of the local conditions by researchers.

After that, we calculated bivariate correlations between the capability metrics and the dependent variable, which is the share of pedestrian trips to and from school by children (or, "share of pedestrian trips"). Additionally, we computed the coefficient of variation (CV) of the capability metrics. Additionally, Pearson parametric correlations were calculated for the correlations with the dependent variable. Based on these indicators, the selection of the appropriate buffer type and level of analysis depends on the signs of the dependent variable and the signs of the obtained correlations (refer to the Table 5).

Table 5: Possible relationships between the correlation sign with the dependent variable and with the expected contribution to the dependent variable, and proposed procedures for selecting buffer type and level of analysis.

\begin{tabular}{ll}
\hline $\begin{array}{l}\text { Situation } \\
\text { (sign for correlation with the dependent variable and } \\
\text { sign of expected contribution to capability indicator) }\end{array}$ & $\begin{array}{l}\text { Procedure } \\
\text { (for selecting buffer type and } \\
\text { level of analysis) }\end{array}$ \\
\hline $\begin{array}{l}\text { Same signs } \\
(+/+) \operatorname{or}(-/-)\end{array}$ & $\begin{array}{l}\text { Select buffer type/level of analysis that presents } \\
\text { the greatest CV and the greatest correlation } \\
\text { (whose statistical significance is greater than 90\%) }\end{array}$ \\
$\begin{array}{l}\text { Opposite signs } \\
(+/-) \text { or }(-/+)\end{array}$ & $\begin{array}{l}\text { Select buffer type/level of analysis that presents } \\
\text { the greatest CV and the lowest correlation } \\
\text { (whose statistical significance is close to null) }\end{array}$ \\
\hline
\end{tabular}

In short, the approach to select the appropriate level of analysis and buffer type of the explanatory variables that can integrate the indicator of mobility capabilities (capability metrics) is to choose the highest $\mathrm{CV}$ and the correlation values depending on the sign of the correlation. This approach aims to build a capability metric with a relationship with the dependent variable (share of pedestrian trips to school) that follows increases in the dependent variable, as well as to capture the variables that present the highest variability of the observed phenomenon. The preference towards variables with low correlations with the other candidate variables seeks to avoid collinearities that can curb the suitability of the pursued capability metric to be compared with the degree of mobility functionings.

Once selected at the appropriate levels of analysis, the capability metrics can be integrated into a composite measure to indicate the capability of schools to promote walking mobility. For that, we identified the relevant thresholds for each metric to classify the schools in a binary way, i.e., 1 (capable), and 0 (non-capable). When no references exist to specify thresholds of the component variables to present the capability of a school to encourage walking to school, we adopted a simplified criterium, i.e., the median value of the variable and the expected correlation sign of each variable with the dependent variable (positive or negative). The expected correlation sign classified the schools above and below the median values as capable (1) or non-capable (0).

According to this procedure, the capability metrics (continuous values) could be converted to binary values that are relevant for the appraisal of the conditions that might enable the achievement of walking to and from school. For the aggregation of the binary variables into a composite measure, equal weights were assumed for the three themes covered (street network, road safety, and the built environment). For the metrics composing each capability theme, equal weight was also 
assumed, which varied therefore according to the number of metrics incorporated within each theme.

Thus, the obtained indicator of mobility capabilities enabled the classification of schools in five levels of mobility capabilities: i) Extreme difficulty; ii) Severe difficulty; iii) Moderate difficulty; iv) Mild difficulty; and v) No difficulty. Each level of mobility capability is associated with a defined range of values of the indicator of mobility capabilities. These followed the framework of the World Health Organization's ICF model, which is adopted in other applications of the CA (Trani, Bakhshi, and Biggeri 2011; Saleeby 2007).

Once grouped into five levels of mobility capabilities, we could evaluate the mobility agency of each school, i.e., the corresponding capacity to promote pedestrian mobility (functionings). For that, the expected shares of pedestrian trips to school (upper and lower bounds) were assigned to each level of mobility capabilities. Accordingly, the higher the level of mobility capability of a school (i.e., the better the street network, traffic safety and built environment for walking), the more capable is the school's environment to promote higher shares of pedestrian trips. So, a school's mobility agency can be obtained by subtracting the dependent variable (current share of pedestrian trips) from the closest value of the expected share of pedestrian trips, which can be either positive (above the upper bound) or negative (below the lower bound), as illustrated in Figure 3. For example, a school with "severe difficulty" mobility levels would be expected to have pedestrian trip shares between $30 \%$ to $45 \%$, while a school with "mild difficulty" levels would range $60 \%$ to $75 \%$. In the example of the figure below, the school in blue has a $60 \%$ pedestrian trip share, meaning that it is 15 percentunits above the maximum expectable share of pedestrian trips. As such, the school presents a positive agency, i.e., its share of pedestrian trips is above expectations. Conversely, the school in red is 30 percent-units below expected pedestrian trip share (negative agency), meaning that there are barriers in converting capabilities to functionings.

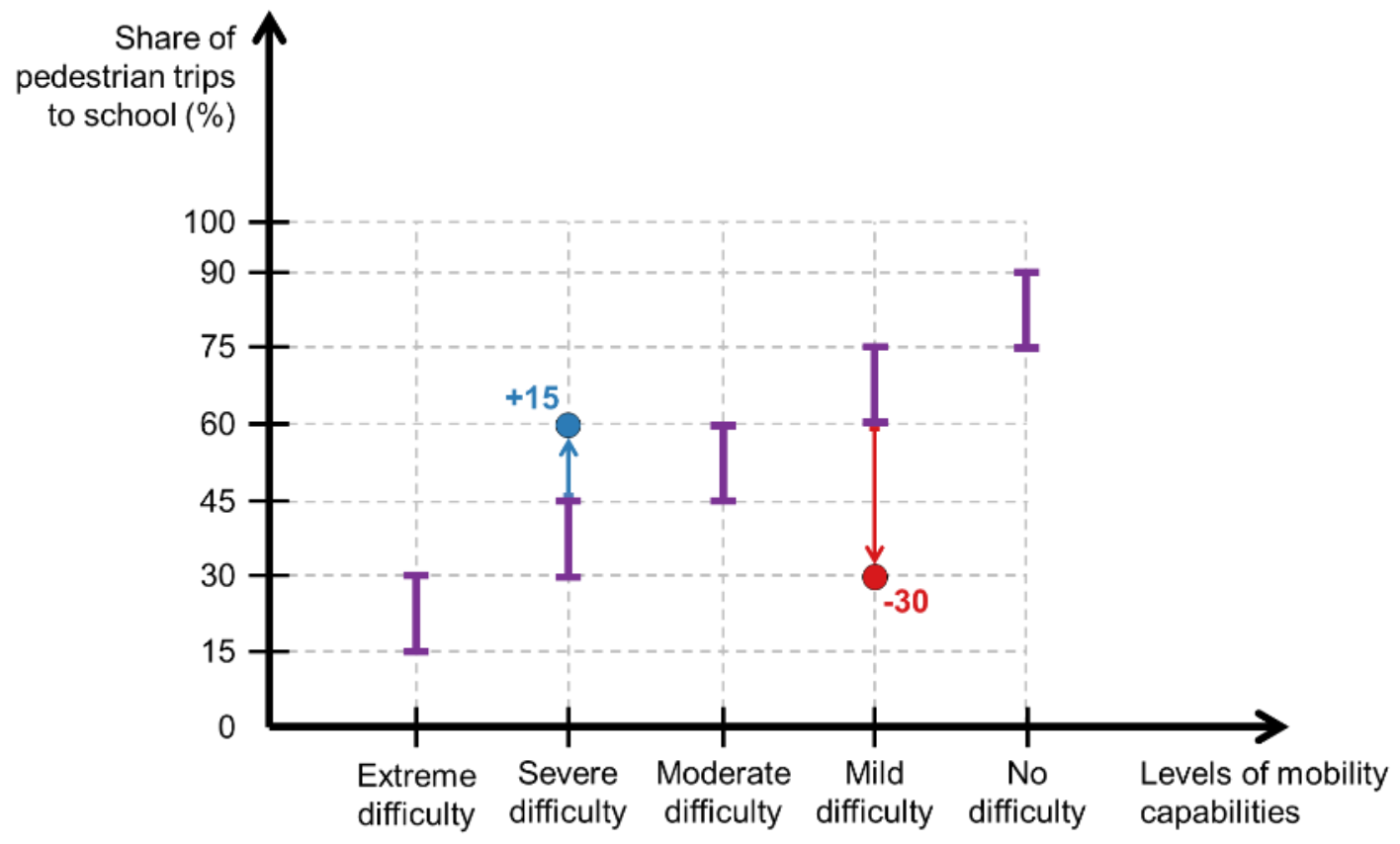

Figure 3: Schematic representation of the calculation of mobility agency according to share of pedestrian trips and levels of mobility capabilities. 
The agency of schools is at the core of the study here presented, in addition to the share of pedestrian trips ( $y$-axis) and the levels of mobility capabilities ( $x$-axis). Some school environments have high shares of pedestrians trips despite the poor conditions to walk (and vice-versa). Such results allowed for the appreciation of disparities in pedestrian mobility, mainly the ones related to the type of school (public/private), the region of the city (low-income outskirts/economic expansion area), and the collected conversion factors, such as the income, the ethnic composition and the walking time to school. These were assessed mainly through thematic maps and T-tests for difference of means, which are presented in the following section.

The methodology previously described is summarized schematically in Figure 4, as follows.

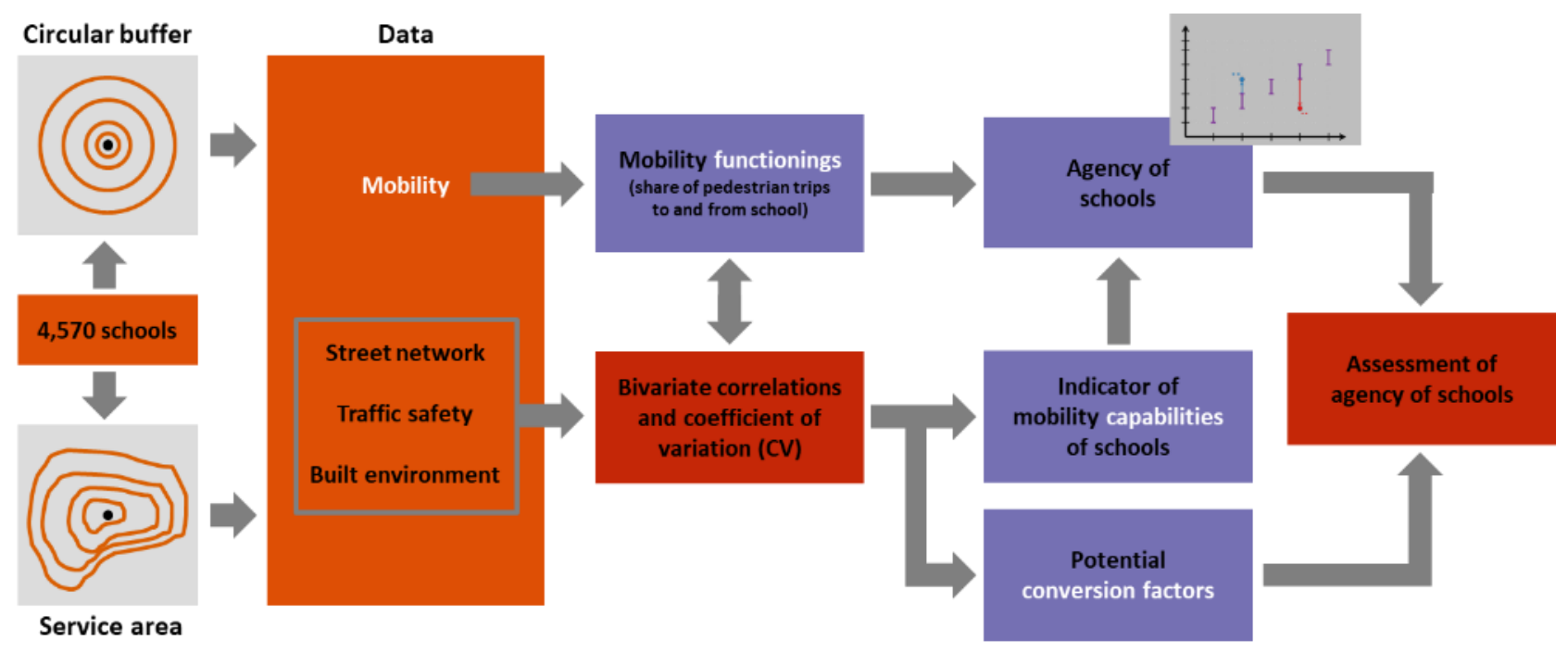

Figure 4: Schematic representation of the adopted methodological steps.

\section{Results}

Analyzing the scenario of the schools' surroundings in comparison with the city of São Paulo (Table 6), the population density and per capita income are slightly higher for the former one while the percentage of children (aged 0 to 6 ) is almost the same for both. Also, the percentage of the population with high social vulnerability is smaller for the schools' surroundings than for São Paulo. This outcome is likely to represent some bias of our sample towards better socio-economic conditions than the average of the city.

Table 6: Average values of selected measures regarding the surroundings of analyzed schools (service area $1000 \mathrm{~m}$ ) as

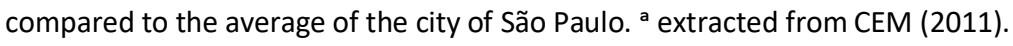

\begin{tabular}{lll}
\hline Measure & $\begin{array}{l}\text { Average of } \\
\text { school surroundings }\end{array}$ & $\begin{array}{l}\text { Average } \\
\text { São Paulo }{ }^{\text {a }}\end{array}$ \\
\hline Population density, urban area $\left(\mathrm{hab} / \mathrm{km}^{2}\right)$ & 14078 & 12165 \\
Per capita income (R\$) & 1454 & 1128 \\
Percentage of population aged 0 to 6 & $8.4 \%$ & $8.9 \%$ \\
Perc. of pop. with high social vulnerability & $11.7 \%$ & $15.6 \%$ \\
\hline
\end{tabular}


The distribution of pedestrian trips obtained through the data of the Origin-Destination survey performed by METRO-SP is illustrated in Figure 5. The central and east regions of São Paulo show a higher share of pedestrian trips than in the West and the South.

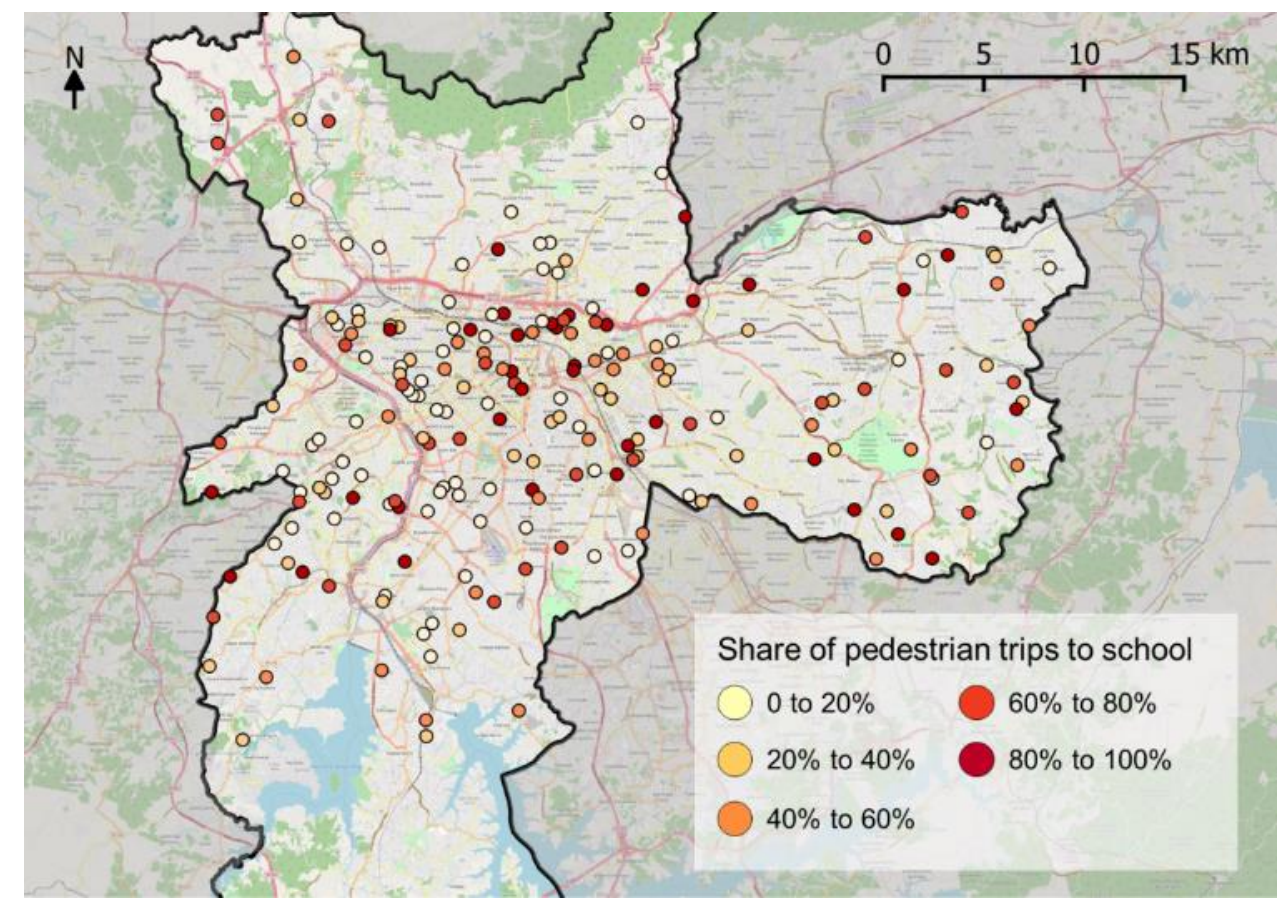

Figure 5: Share of pedestrian trips to school

To analyze the mobility capabilities of each school some metrics were selected within each capability theme of interest (street network, traffic safety and built environment). In Table 7 each mobility metric is presented at the selected buffer type and levels of analysis that was found appropriate. The relevant threshold used to classify the schools as capable or non-capable is also presented. For the metrics composing each capability theme, equal weight was assumed summing up to a maximum weight of 4 , as presented in the previous section Methods.

Table 7: List of variables composing the indicator of mobility capabilities (mobility metrics) and the relevant threshold for the identification of mobility capability (sign of expected contribution and median value).

${ }^{\text {a }} \mathrm{CB}=$ circular buffer; $\mathrm{SA}=$ service area.

\begin{tabular}{lllll}
\hline Mobility metric & Theme & $\begin{array}{l}\text { Buffer type \& } \\
\text { level of analysis }\end{array}$ & $\begin{array}{l}\text { Relevant } \\
\text { threshold }\end{array}$ & Weight \\
\hline Closeness centrality & Street network & SA 2000m & $\geq 5.14 \times 10^{-4}$ & 2 \\
Intersection density & Street network & SA 500m & $\geq 114$ & 2 \\
Car-pedestrian crashes & Traffic safety & SA 2000m & $\leq 28$ & 4 \\
Coverage of sidewalks & Built environment & SA 2000m & $\geq 95 \%$ & 1 \\
Coverage of vegetation & Built environment & SA 500m & $\geq 85 \%$ & 1 \\
Presence of open sewage & Built environment & SA 1000m & $\leq 1 \%$ & 1 \\
Presence of litter & Built environment & SA 1000m & $\leq 3 \%$ & 1 \\
\hline & & & Total & 12
\end{tabular}


The results obtained for capability metrics (Figure 6) reveal the lowest level of traffic safety in the central part of the city, where the highest number of pedestrian-car crashes occurred, and also the lowest level regarding street network metrics. On the other hand, the city's central regions stands out for the quality of the built environment for walking, as expected. Besides, the built environment metrics showed to be also higher in the west portion of the city in comparison to others. Street network and traffic safety metrics did not present significant differences amongst them.

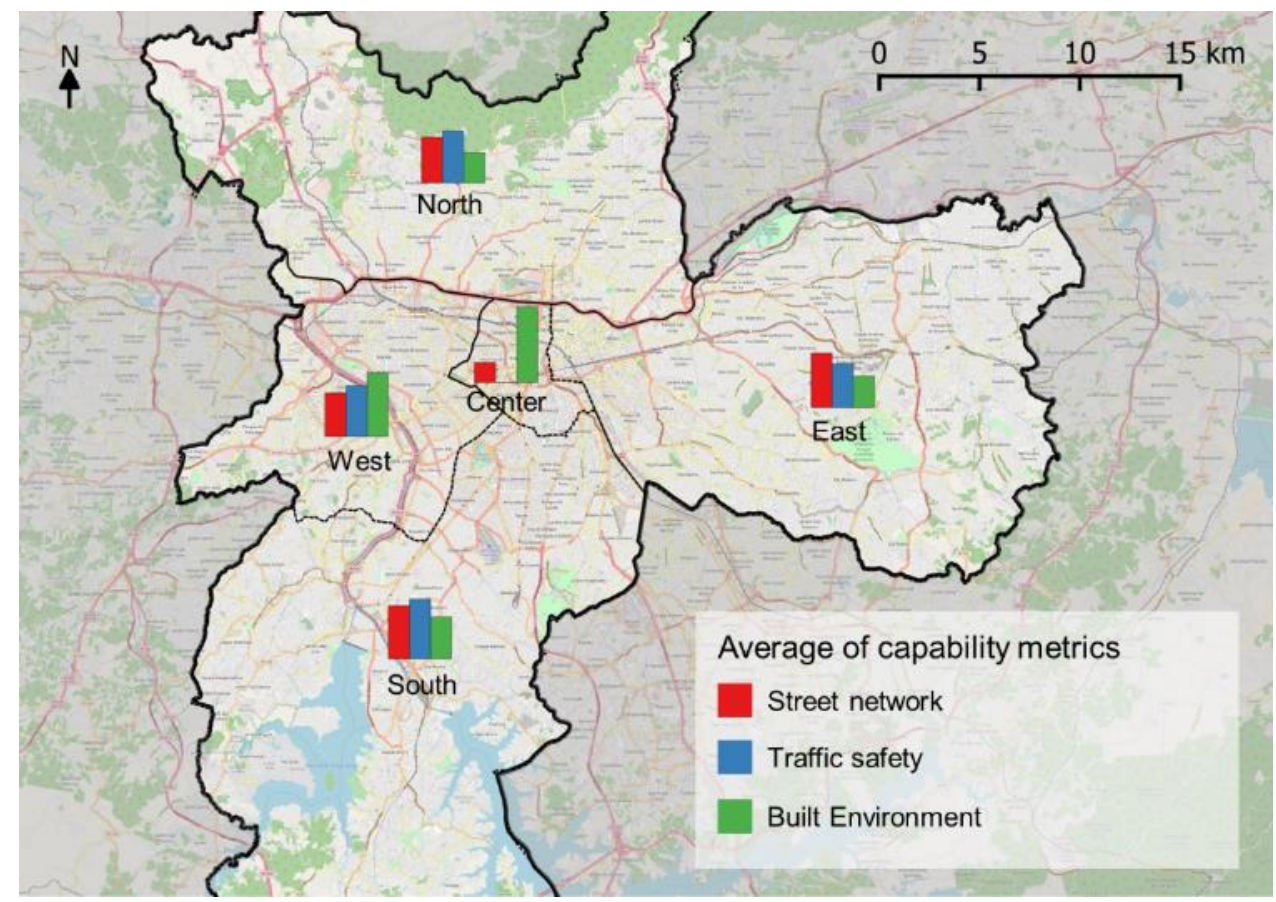

Figure 6: Average of mobility capability metrics of schools

The levels of mobility capabilities were defined based on the number of mobility capabilities that each school presented, as displayed on Table 8. The majority of schools were classified as having "moderate difficulty" level of mobility capabilities (approximately $41 \%$ ), followed by "severe difficulty" (approximately 29\%). Only 3\% of the schools have a "no difficulty" level of mobility. These outcomes are likely to reinforce the hypothesis that most of the schools' surroundings in the city do not present satisfactory walking conditions.

Table 8: Number of mobility capabilities associated to the five levels of mobility capabilities and their distribution in analyzed schools.

\begin{tabular}{lll}
\hline $\begin{array}{l}\text { Number of } \\
\text { mobility capabilities }\end{array}$ & $\begin{array}{l}\text { Level of } \\
\text { mobility capabilities }\end{array}$ & $\begin{array}{l}\text { Number of } \\
\text { schools }(\mathrm{N})\end{array}$ \\
\hline 0 to 2 & Extreme difficulty & 18 \\
3 to 5 & Severe difficulty & 59 \\
6 to 8 & Moderate difficulty & 84 \\
9 to 10 & Mild difficulty & 36 \\
11 to 12 & No difficulty & 6 \\
\hline
\end{tabular}

In contrast to the share of pedestrian trips pattern previously discussed and illustrated in Figure 5, the spatial distribution of the levels of mobility capabilities of schools (Figure 7) shows that the 
highest levels of difficulties related to the mobility capabilities are located in the central and east regions of the city. The lowest levels of difficulties are observed in the west and south parts of São Paulo.

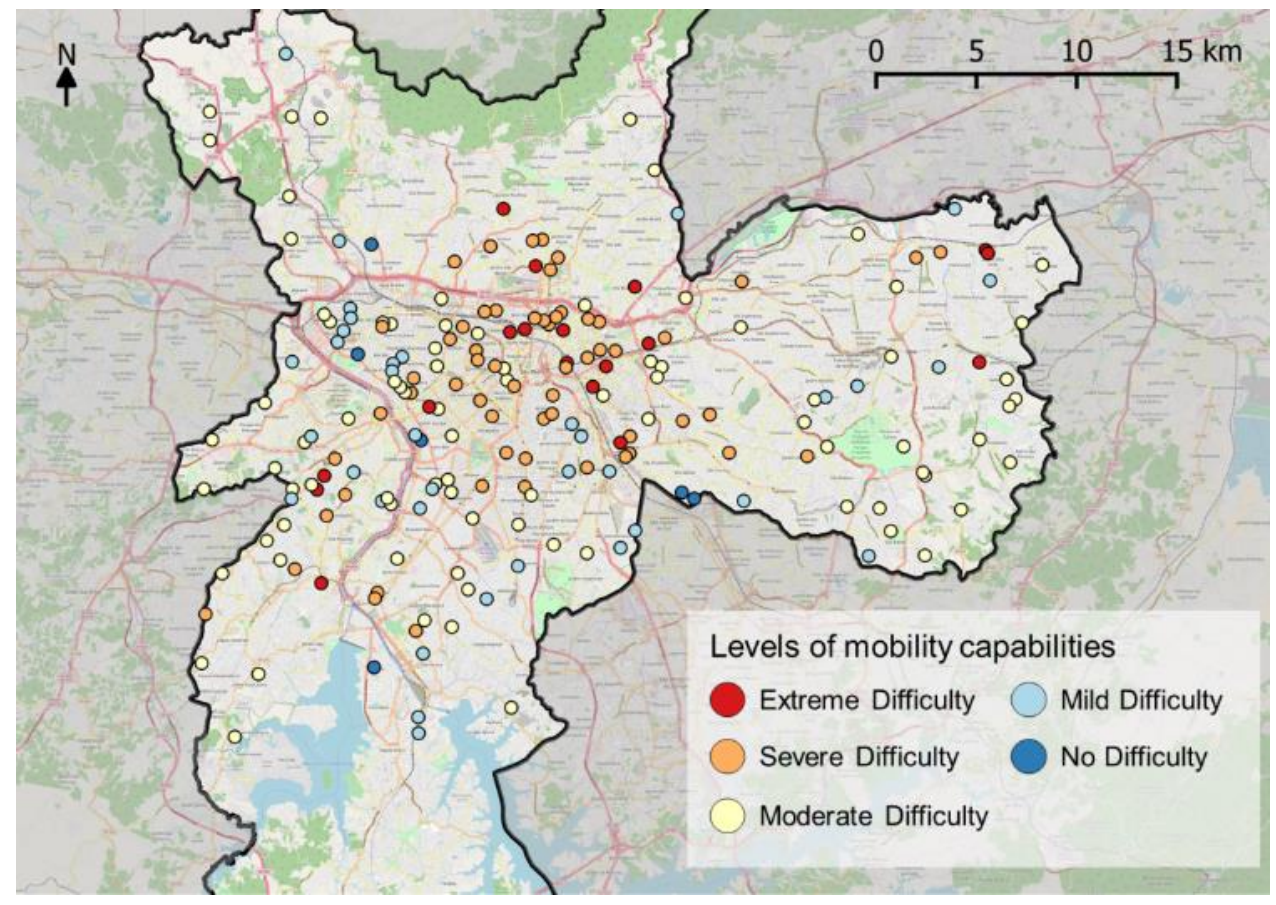

Figure 7: Levels of mobility capabilities of schools

The levels of agency of schools reflect the relation between the share of pedestrian trips and the levels of mobility difficulties. The result is presented in Figure 8 , which displays a predominance of schools with positive levels of agency in the central and east parts of the city (i.e., higher than expected pedestrian trip shares in face of mobility capabilities evaluated) and the majority number of schools with negative levels of agency in the west and south regions (i.e., lower pedestrian trip shares in face of mobility capabilities evaluated). 


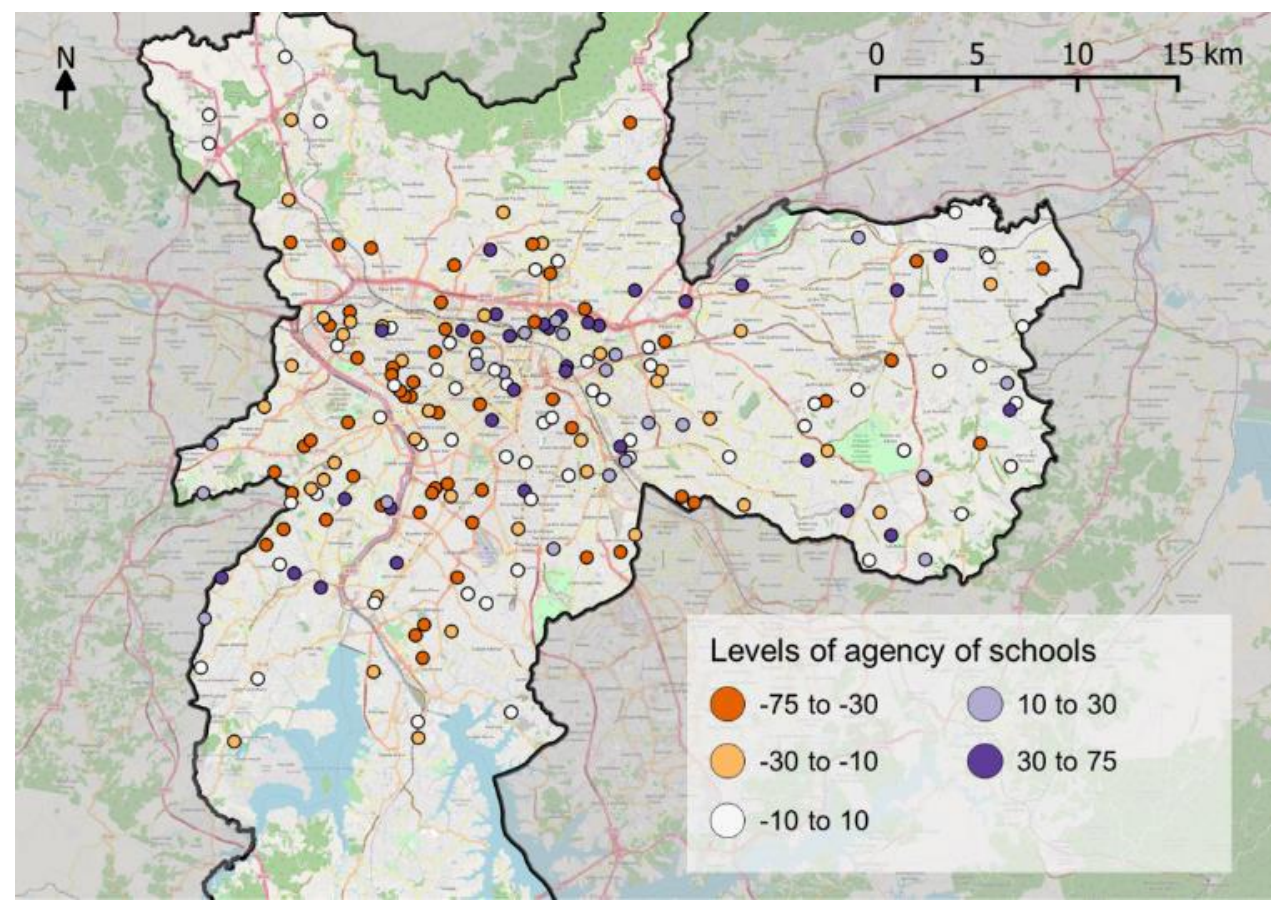

Figure 8: Levels of agency of schools

The results were analyzed and sorted by type of school (Table 9). The average share of pedestrian trips stands out for public schools, accounting for $54 \%$ of the total trips. For private schools this share corresponds to $26 \%$ of the total trips. However, public schools display the highest levels of mobility difficulties, with approximately $82 \%$ of the schools classified from moderate to extreme difficulty levels. On the other hand, $65 \%$ of the private schools were classified from no difficulty to moderate difficulty levels.

Table 9: Average share of pedestrian trips to school and levels of mobility capabilities according to school type (public/private).

\begin{tabular}{lllllll}
\hline Type of & Share of & \multicolumn{4}{l}{ Number (percentage) of schools in levels of mobility capabilities } \\
school (N) & $\begin{array}{l}\text { pedestrian trips } \\
\text { (average) }\end{array}$ & $\begin{array}{l}\text { Extreme } \\
\text { difficulty }\end{array}$ & $\begin{array}{l}\text { Severe } \\
\text { difficulty }\end{array}$ & $\begin{array}{l}\text { Moderate } \\
\text { difficulty }\end{array}$ & $\begin{array}{l}\text { Mild } \\
\text { difficulty }\end{array}$ & difficulty \\
\hline Public (109) & $54 \%$ & $11(10 \%)$ & $34(31 \%)$ & $45(41 \%)$ & $15(14 \%)$ & $4(4 \%)$ \\
Private (94) & $26 \%$ & $7(7 \%)$ & $25(27 \%)$ & $39(41 \%)$ & $21(22 \%)$ & $2(2 \%)$ \\
\hline
\end{tabular}

We compared the parameters regarding the surroundings of schools with negative and positive agency (refer to Table 10). Regarding the street network parameters (average circuity and street density) and population density, there are no significant differences. However, all parameters to the built environment showed a significant difference after performing a T-test analysis. The most relevant ones were the percentage of black population and percentage of areas/population with a high social vulnerability which were higher for schools with positive agency; percentage of white population, per capita income and coverage of street lighting, paved streets and vegetation, which were higher for schools with a negative agency. As for the average walking time, it also presented a significant difference. Schools with a positive agency presented higher average walking time than the ones with a negative agency. 
This is a preprint of an article published by Taylor \& Francis in the Journal of Human Development and Capabilities on March 24th 2020, available online: http://doi.org/10.1080/19452829.2020.1745163

Table 10: Comparison of surroundings of schools with a negative $(\mathrm{N}=94)$ or positive agency $(\mathrm{N}=52) .{ }^{\text {a }} \mathrm{CB}=$ circular buffer; $\mathrm{SA}=$ service area. ${ }^{\mathrm{b}}$ Schools with null agency $(\mathrm{N}=57)$ were not considered in the analysis. ${ }^{\mathrm{c}}$ Equal variances not assumed.

\begin{tabular}{|c|c|c|c|c|c|}
\hline Measure & $\begin{array}{l}\text { Buffer type } \\
\& \text { level of } \\
\text { analysis }^{\text {a }}\end{array}$ & $\begin{array}{l}\text { Mean for } \\
\text { schools with } \\
\text { negative agency } \\
\text { (from }-75 \text { to }-10 \text { ) }\end{array}$ & $\begin{array}{l}\text { Mean for } \\
\text { schools with } \\
\text { positive agency } \\
\text { (from } 10 \text { to } 75 \text { ) }\end{array}$ & $\begin{array}{l}\text { Average } \\
\text { difference }\end{array}$ & $\begin{array}{l}\text { T-test for } \\
\text { difference of } \\
\text { means (Sig.) }^{c}\end{array}$ \\
\hline Average circuity & CB 500m & 1.0352 & 1.0402 & $0.0050(5 \%)$ & $0.911(0.364)$ \\
\hline Street density & CB $500 m$ & 14.5 & 14.0 & $-0.6(-4 \%)$ & $-1.013(0.314)$ \\
\hline Population density (hab/km²) & CB 2000m & 10076 & 11488 & $1413(14 \%)$ & $2.004(0.049)$ \\
\hline Percentage of white population & SA $500 m$ & $76 \%$ & $64 \%$ & $-12 \%$ & $-4.939(0.000)$ \\
\hline Percentage of black population & SA $500 m$ & $4 \%$ & $6 \%$ & $2 \%$ & $3.896(0.000)$ \\
\hline Percentage of population aged 0 to 6 & SA $500 \mathrm{~m}$ & $7 \%$ & $8 \%$ & $1 \%$ & $3.597(0.001)$ \\
\hline Perc. of areas with high social vulnerability & SA $2000 \mathrm{~m}$ & $4 \%$ & $10 \%$ & $6 \%$ & $2.708(0.009)$ \\
\hline Perc. of pop. with high social vulnerability & CB $1000 \mathrm{~m}$ & $8 \%$ & $16 \%$ & $9 \%$ & $3.349(0.001)$ \\
\hline Percentage of urban area & CB $1000 \mathrm{~m}$ & $97 \%$ & $99 \%$ & $2 \%$ & $2.200(0.030)$ \\
\hline Per capita income (R\$/hab.) & SA $2000 \mathrm{~m}$ & 2113 & 1300 & $-813(-38 \%)$ & $-3.926(0.000)$ \\
\hline Coverage of street lighting & SA $1000 \mathrm{~m}$ & $94 \%$ & $89 \%$ & $-5 \%$ & $-2.622(0.011)$ \\
\hline Coverage of paved streets & SA $1000 \mathrm{~m}$ & $94 \%$ & $90 \%$ & $-4 \%$ & $-2.231(0.029)$ \\
\hline Coverage of vegetation & SA $1000 \mathrm{~m}$ & $80 \%$ & $71 \%$ & $-9 \%$ & $-2.577(0.012)$ \\
\hline Average walking time (min) & - & 12.5 & 16.3 & $3.8(31 \%)$ & $2.484(0.015)$ \\
\hline
\end{tabular}

Table 11 presents the results comparing means for private and public schools, considering only the measures identified as relevant in the previous analysis. The differences that can be pointed out from this comparison are: (i) share of pedestrian trips, being more than two times higher for public schools; (ii) agency, while for public schools the mean is positive for private schools the mean is negative and three times higher in absolute value; (iii) percentage of white population, which is $12 \%$ lower for public schools; (iv) per capita income, which is significantly lower for public schools (approximately 40\%) and (v) average walking time, with over $30 \%$ more minutes per trip for public schools. All of the aforementioned differences are statistically significant at the $99 \%$ level. 
Table 11: Comparison of means of selected variables between private schools $(\mathrm{N}=94)$ and public schools $(\mathrm{N}=109) .{ }^{\mathrm{a}}$ Equal variances not assumed. ${ }^{b}$ Low mobility capability: extreme, severe and moderate.

\begin{tabular}{|c|c|c|c|c|}
\hline Measure & $\begin{array}{l}\text { Mean for } \\
\text { private } \\
\text { schools }\end{array}$ & $\begin{array}{l}\text { Mean for } \\
\text { public } \\
\text { schools }\end{array}$ & $\begin{array}{l}\text { Average } \\
\text { difference }\end{array}$ & $\begin{array}{l}\text { T-test for } \\
\text { difference of } \\
\text { means (Sig.) }\end{array}$ \\
\hline Share of pedestrian trips & $26 \%$ & $54 \%$ & $29 \%$ & $6.649(0.000)$ \\
\hline Agency & -20 & 6 & 26 & $6.306(0.000)$ \\
\hline$\%$ of schools with low mobility capability ${ }^{\text {b }}$ & $76 \%$ & $83 \%$ & $7 \%$ & $1.221(0.224)$ \\
\hline Population density (hab/km²) & 10668 & 10895 & $227(2 \%)$ & $0.421(0.674)$ \\
\hline Percentage of white population & $77 \%$ & $65 \%$ & $-12 \%$ & $-6.197(0.000)$ \\
\hline Perc. of pop. with high social vulnerability & $8 \%$ & $14 \%$ & $6 \%$ & $3.201(0.002)$ \\
\hline Per capita income (R\$/hab.) & 2302 & 1375 & $-927(-40 \%)$ & $-4.919(0.000)$ \\
\hline Average walking time (min) & 12.0 & 15.6 & $3.7(31 \%)$ & $3.047(0.003)$ \\
\hline
\end{tabular}

When regarding the differences between the nurseries (children aged 0-3) and preschools (aged 46), nevertheless, most of the differences calculated were insignificant, indicating there is not a strong influence of the age of children on the degrees of capabilities and agencies of schools. One exception refers to the agency of schools, in which a positive agency (9) is identified among nurseries, whereas in preschools there is a negative average agency, as follows.

Table 12: Comparison of means of selected variables between nurseries $(\mathrm{N}=53)$ and preschools $(\mathrm{N}=62) .{ }^{a}$ Integrated preschool \& nursery schools ( $\mathrm{N}=88$ ) were not considered in the analysis. ${ }^{\mathrm{b}}$ Equal variances not assumed. ${ }^{\mathrm{c}}$ Low mobility capability: extreme, severe and moderate.

\begin{tabular}{|c|c|c|c|c|}
\hline Measure & $\begin{array}{l}\text { Mean for } \\
\text { nurseries }\end{array}$ & $\begin{array}{l}\text { Mean for } \\
\text { preschools a }\end{array}$ & $\begin{array}{l}\text { Average } \\
\text { difference }\end{array}$ & $\begin{array}{l}\text { T-test for } \\
\text { difference of } \\
\text { means (Sig.) }^{b}\end{array}$ \\
\hline Share of pedestrian trips & $57 \%$ & $48 \%$ & $-9 \%$ & $1.510(0.134)$ \\
\hline Agency & 9 & -3 & -12 & $2.104(0.038)$ \\
\hline$\%$ of schools with low mobility capability ${ }^{c}$ & $83 \%$ & $73 \%$ & $-10 \%$ & $1.351(0.180)$ \\
\hline Population density (hab/km²) & 10637 & 10704 & $67(0 \%)$ & $-0.090(0.928)$ \\
\hline Percentage of white population & $64 \%$ & $68 \%$ & $4 \%$ & $-1.425(0.157)$ \\
\hline Perc. of pop. with high social vulnerability & $16 \%$ & $14 \%$ & $-2 \%$ & $0.683(0.496)$ \\
\hline Per capita income (R\$/hab.) & 1351 & 1516 & $165(12 \%)$ & $-0.729(0.467)$ \\
\hline Average walking time (min) & 15.8 & 14.9 & $-0.9(6 \%)$ & $0.568(0.571)$ \\
\hline
\end{tabular}




\section{Conclusion}

In the study presented, a set of variables were collected for the surroundings of 203 preschools and nurseries in São Paulo (Brazil). That enabled the development of an indicator of mobility capabilities covering three themes (street network, traffic safety and the built environment), and the assessment of the pedestrian share of trips in the access to schools. Once related, the levels of mobility capabilities and the shares of pedestrian trips (mobility functionings) allowed the computation of the schools' mobility agencies, i.e., the capacity of schools to convert abilities to achieved functionings. The mobility agency values of a school could be positive or negative, indicating the share of pedestrian trips that lie above and below the expected trip share, respectively.

For the construction of the indicator of mobility capabilities, the search for the capability metrics and conversion factors at the appropriate level of analysis (buffer distance) and type (circular buffer vs. service area) provided important considerations regarding the kinds of measures that seem relevant for assessing the surroundings of schools and recommendations regarding the extent and boundaries of such surroundings according to the feature considered. Within the indicator of mobility capabilities, all metrics presented information related to the service areas, despite presenting levels of analysis equally distributed among the available buffer distances $(500 \mathrm{~m}, 1000 \mathrm{~m}$ and $2000 \mathrm{~m}$ ). The conversion factors presented principally service areas in all levels of analysis available. Nevertheless, the circular buffers, whose calculation is than simpler than for the service areas, seemed to be sufficient to identify certain conversion factors for assessing the agency of schools, such as the population with high social vulnerability (distance of $1000 \mathrm{~m}$ ) and the population density (distance of $2000 \mathrm{~m}$ ). This is pertinent when one needs more straightforward methods to undertake preliminary studies and to draft public policies.

The identification of relevant features that seem to affect the ability of schools to convert the available resources (capabilities) into mobility functionings is notable. First, positive agencies were found principally among public schools (and also among public and private nurseries), which might represent the willingness of such children and caregivers to walk to and from schools in spite of unfavorable conditions to walk. Nevertheless, positive agencies also seem to be associated with denser neighborhoods, lower incomes and higher walking times, which might reflect the lack of alternatives to access schools rather than walking. Correspondingly, negative agencies were identified mainly among private schools, which might indicate the role of the income and the distance from home (as indicated by the average walking time) to reduce one's ability to convert the mobility capabilities into the achieved access to school through walking.

Those remarks can be helpful when drafting public policies to promote walking as a primary way to access public and private schools. Positive agencies suggest prioritizing the upgrading of existing pedestrian trips to school that are performed under inadequate conditions (mainly public schools and children in nurseries, aged 0-3). In the other way, negative agencies indicate a better match of strategies for promoting walking (e.g., marketing, advocacy, campaigns) in regions with a low pedestrian share of trips and a rather consolidated infrastructure (most of them private schools and preschool-age children, aged 4-6).

The adopted aggregation method to compose the indicator of mobility capabilities, as formulated by Biggeri and Libanora (2011) and Chakravarty and d'Ambrosio (2006), was found to be appropriate to measure the capabilities that seem relevant to walk to school. The method differs from the additive 
compensatory ones that are commonly applied in the development of multicriteria indexes in the transport domain, since the compensation of a metric's low performance by a high score by another metric is minimized in this approach.

Setting the median as the threshold value for all variables presents convenient simplifications regarding the classification of the schools in capable (1) and non-capable (0) for each capability metric, since it identifies values that divide the analyzed schools in two groups with the same size. However, that exempts the definition of relevant threshold from the public eye, besides being driven exclusively by the data available. This disadvantage is mitigated since the parameters with greater dispersion (greater $\mathrm{CV}$ ) are preferred for the selection of the capability metrics and the conversion factors. Nevertheless, we recommend organizing public discussion on the parameters set to correctly identify the thresholds that are relevant for each metric. The same issue of public discussion and methodological simplification can be transposed to the eliciting of weights, since nonequal weights can be elicited either for variables within the same theme or for the relationship between the themes that are being covered.

The concept of school agency here presented does not encompass possible underlying disparities and constraints related to walking. Especially in developing countries, it is a relevant issue when one walks either as an optional mode of transport (rather than using the transit, being driven, etc.) or as the only mode of transport available (due to non-coverage of public transport, to financial limitations, etc.). That could be appraised in further studies by including the individual reasons and motivations to walk to and from school and by considering an indicator of public transport accessibility and car ownership.

To develop further studies, some suggestions are outlined: i) a deeper analysis of the influence of age on the development of mobility capabilities, functionings and agency (rather than stratifying by nurseries and preschools); ii) the inclusion of security and land use datasets into the indicator of mobility capabilities and potential conversion factors; iii) the adoption of participatory methods to select the capability metrics, to identify relevant thresholds and to elicit weights of the indicator's metrics and composing themes; iv) the consideration of the distances from children's homes to school rather than its estimation from the provided trip length; $v$ ) the influence of the parents' employment on the mobility behavior of children, i.e., the effect of parental absence on children's time use, as in Cuong \& Linh (2016); and vi) the assessment of children's independent mobility, i.e., when they are not escorted by adults. 


\section{References}

Babb, Courtney, Doina Olaru, Carey Curtis, and Dave Robertson. 2016. "Children's Active Travel, Local Activity Spaces and Wellbeing: A Case Study in Perth, WA." Travel Behaviour and Society. doi:10.1016/j.tbs.2017.06.002.

Ballet, Jérôme, Mario Biggeri, and Flavio Comim. 2011. “Children's Agency and the Capability Approach: A Conceptual Framework." In Children and the Capability Approach, edited by Mario Biggeri, Jérôme Ballet, and Flavio Comim, 1st ed., 22-45. New York (USA): Palgrave Macmillan.

Beyazit, Eda. 2011. "Evaluating Social Justice in Transport: Lessons to Be Learned from the Capability Approach." Transport Reviews 31 (1): 117-34. doi:10.1080/01441647.2010.504900.

Biggeri, Mario, Jérôme Ballet, and Flavio Comim, eds. 2011. Children and the Capability Approach. Hampshire, UK: Palgrave Macmillan.

Biggeri, Mario, and Renato Libanora. 2011. "From Valuing to Evaluating: Tools and Procedures to Operationalize the Capability Approach." In Children and the Capability Approach, edited by M. Biggeri, J. Ballet, and F. Comim, 79-106. Hampshire, UK: Palgrave Macmillan.

Biggeri, Mario, Renato Libanora, Stefano Mariani, and Leonardo Menchini. 2006. "Children Conceptualizing Their Capabilities: Results of a Survey Conducted during the First Children's World Congress on Child Labour *." Journal of Human Development 7 (1): 59-83. doi:10.1080/14649880500501179.

Boeing, Geoff. 2017. "OSMnx: New Methods for Acquiring, Constructing, Analyzing, and Visualizing Complex Street Networks." Computers, Environment and Urban Systems 65. Elsevier Ltd: 12639. doi:10.1016/j.compenvurbsys.2017.05.004.

Carver, Alison, Jo Salmon, Karen Campbell, Louise Baur, Sarah Garnett, and David Crawford. 2005. "How Do Perceptions of Local Neighborhood Relate to Adolescents' Walking and Cycling?" American Journal of Health Promotion 20 (2): 139-47. doi:10.4278/0890-1171-20.2.139.

CEM. 2011. "2010 Brazilian Demographic Census (Georeferenced Database, Vector:Polygon)." São Paulo, Brazil: Centro de Estudos da Metrópole (CEM). http://www.fflch.usp.br/centrodametropole/upload/arquivos/Censo_2010_2.7z.

Chakravarty, Satya R., and Conchita D'Ambrosio. 2006. "The Measurement of Social Exclusion." Review of Income and Wealth 52 (3): 377-98.

Clifton, K., and F. Moura. 2017. "A Conceptual Framework for Understanding Latent Demand: Accounting for Unrealized Activities and Travel." 96th Annual Meeting of the Transportation Research Board, Washington, USA, 8-12 Janeiro, 1-12.

Comim, Flavio, Mozaffar Qizilbash, and Sabina Alkire, eds. 2008. The Capability Approach: Concepts, Measures and Applications. Cambridge (UK): Cambridge University Press.

Cuong, Nguyen Viet, and Vu Hoang Linh. 2016. "Should Parents Work Away from or Close to Home? The Effect of Parental Absence on Children's Time Use in Vietnam." Journal of Human Development and Capabilities 17 (1): 110-24. doi:10.1080/19452829.2015.1103711.

Harkot, Marina Kohler, Mateus Humberto Andrade, Mariana Giannotti, and Paula Santoro. 2017. "Gender and Walking: Does the Quality of Built Environment Equally Promote Walking for Women and Men?" In Cidades de Pedestres, edited by Victor Andrade and Clarisse Cunha Linke, 1st ed. Rio de Janeiro, Brazil: Babilônia Editorial.

IBGE. 2011. "2010 Brazilian Demographic Census. Characteristics of Population and Households: Results." Rio de Janeiro, Brazil. http://www.ibge.gov.br/home/estatistica/\%0Apopulacao/censo2010/caracteristicas_da_popul acao/\%0Aresultados_do_universo.pdf.

Kerr, Jacqueline, Dori Rosenberg, James F. Sallis, Brian E. Saelens, Lawrence D. Frank, and Terry L. Conway. 2006. "Active Commuting to School: Associations with Environment and Parental Concerns." Medicine and Science in Sports and Exercise 38 (4): 787-94. doi:10.1249/01.mss.0000210208.63565.73.

Kuklys, Wiebke. 2005. Amartya Sen's Capability Approach: Theoretical Insights and Empirical Applications. Berlin: Springer. 
Leßmann, Ortrus. 2016. "Is There a Starting Gate to Responsible Adulthood? Childhood, Equality of Opportunity and the Capability Approach." Journal of Ethical Perspectives 4: 709-28. doi:10.2143/EP.23.4.3188788.

Lucas, Karen, Bert van Wee, and Kees Maat. 2016. "A Method to Evaluate Equitable Accessibility: Combining Ethical Theories and Accessibility-Based Approaches." Transportation 43 (3): 473 90. doi:10.1007/s11116-015-9585-2.

Martens, Karel. 2012. "Justice in Transport as Justice in Accessibility: Applying Walzer's 'Spheres of Justice' to the Transport Sector." Transportation 39 (6): 1035-53. doi:10.1007/s11116-0129388-7.

- - - 2017. Transport Justice: Designing Fair Transportation Systems. Edited by Routledge.

Mitra, Raktim. 2013. "Independent Mobility and Mode Choice for School Transportation: A Review and Framework for Future Research." Transport Reviews 33 (1): 21-43. doi:10.1080/01441647.2012.743490.

Nussbaum, Marta C. 2007. Frontiers of Justice.

Pereira, R, T Schwanen, and D Banister. 2017. "Distributive Justice and Equity in Transportation." Transport Reviews 37 (2). Taylor \& Francis: 170-91. doi:10.1080/01441647.2016.1257660.

Richter, Jochen, Margareta Friman, and Tommy Garling. 2010. "Review of Evaluations of Soft Transport Policy Measures." Transportation: Theory and Application 2 (1): 5-18. https://blogs.otago.ac.nz/amc/research/files/2011/07/Richter-Review-of-Evals-of-soft-transpolicy-measures.pdf.

Robeyns, Ingrid. 2003. "The Capability Approach: An Interdisciplinary Introduction." 3rd International Conference on the Capability Approach, Pavia, Italy, 1-57. doi:10.1111/j.14679760.2006.00263.x.

- - . 2017. Wellbeing, Freedom and Social Justice: The Capability Approach Re-Examined. Cambridge (UK): OpenBook Publishers. doi:10.11647/OBP.0130.

Saleeby, Patricia Welch. 2007. "Applications of a Capability Approach to Disability and the International Classification of Functioning, Disability and Health (ICF) in Social Work Practice." Journal of Social Work in Disability \& Rehabilitation 6 (1-2): 217-32. doi:10.1300/J198v06n01_12.

Schoeppe, Stephanie, Mitch J. Duncan, Hannah Badland, Melody Oliver, and Carey Curtis. 2013. "Associations of Children's Independent Mobility and Active Travel with Physical Activity, Sedentary Behaviour and Weight Status: A Systematic Review." Journal of Science and Medicine in Sport 16 (4). Sports Medicine Australia: 312-19. doi:10.1016/j.jsams.2012.11.001.

SEADE. 2012. "Índice Paulista de Vulnerabilidade Social (IPVS) - Principais Resultados." São Paulo (Brazil). http://indices-ilp.al.sp.gov.br/view/pdf/ipvs/principais_resultados.pdf.

Shliselberg, Rebecca, and Moshe Givoni. 2018. "Motility as a Policy Objective." Transport Reviews 38 (3). Taylor \& Francis: 279-97. doi:10.1080/01441647.2017.1355855.

Shonkoff, Jack P., and Deborah A. Phillips, eds. 2000. From Neurons to Neighborhoods: The Science of Early Childhood Development. Sciences-New York. Washington, D.C.: National Academy Press. http://www.nap.edu/catalog/9824.html.

Sirard, John R., and Megan E. Slater. 2008. "Walking and Bicycling to School: A Review." American Journal of Lifestyle Medicine 2 (5): 372-96. doi:10.1177/1559827608320127.

Smith, Liz, Sarah H. Norgate, Tom Cherrett, Nigel Davies, Christopher Winstanley, and Mike Harding. 2015. "Walking School Buses as a Form of Active Transportation for Children-A Review of the Evidence." Journal of School Health 85 (3): 197-210. doi:10.1111/josh.12239.

Trani, Jean-Francois, Parul Bakhshi, and Mario Biggeri. 2011. "Rethinking Children's Disabilities through the Capability Lens: A Framework for Analysis and Policy Implications." In Children and the Capability Approach, edited by Mario Biggeri, Jérôme Ballet, and Flavio Comim, 1st ed., 245-70. New York (USA): Palgrave Macmillan.

Ulset, Vidar, Frank Vitaro, Mara Brendgen, Mona Bekkhus, and Anne I.H. Borge. 2017. "Time Spent Outdoors during Preschool: Links with Children's Cognitive and Behavioral Development." 
Journal of Environmental Psychology 52. Elsevier Ltd: 69-80. doi:10.1016/j.jenvp.2017.05.007. Van Acker, Veronique, Bert Van Wee, and Frank Witlox. 2010. "When Transport Geography Meets Social Psychology: Toward a Conceptual Model of Travel Behaviour." Transport Reviews 30 (2): 219-40. doi:10.1080/01441640902943453.

van Wee, Bert, and Karst Geurs. 2011. "Discussing Equity and Social Exclusion in Accessibility Evaluations." European Journal of Transport and Infrastructure Research 11 (4): 350-67. Vasconcellos, Eduardo Alcantara. 2018. "Urban Transport Policies in Brazil: The Creation of a Discriminatory Mobility System." Journal of Transport Geography 67 (August): 85-91. doi:10.1016/j.jtrangeo.2017.08.014.

Waygood, Owen, and Adrien Cervesato. 2017. "Transport and Child Well-Being: Case Study of Quebec City." Journal of Transport \& Health 5: S98. doi:10.1016/j.jth.2017.05.256.

WHO. 2013. "How to Use the ICF: A Practical Manual for Using the International Classification of Functioning, Disability and Health (ICF). Exposure Draft for Comment." Geneva (Switzerland). 